\title{
Responsible conduct of research: Global trends, local opportunities
}

AUTHORS:

Theresa M. Rossouw ${ }^{1,2}$

Christa van Zyl ${ }^{3}$

Anne Pope ${ }^{4}$

\section{AFFILIATIONS:}

'Department of Family Medicine, Faculty of Health Sciences, University of Pretoria, Pretoria, South Africa

2Department of Immunology, Faculty of Health Sciences, University of Pretoria, Pretoria, South Africa

${ }^{3}$ Research Coordination, Ethics and Integrity, Human Sciences Research Council, Pretoria, South Africa

${ }^{4}$ Private Law Department, Law Faculty, University of Cape Town, Cape Town, South Africa

\section{CORRESPONDENCE TO: \\ Theresa Rossouw}

EMAIL:

theresa.rossouw@up.ac.za

\section{POSTAL ADDRESS:}

Department of Family Medicine, University of Pretoria, PO Box 667, Pretoria 0001, South Africa

\section{DATES:}

Received: 11 Apr. 2013

Revised: 04 Sep. 2013

Accepted: 10 Sep. 2013

\section{KEYWORDS:}

responsible; conduct; research; integrity; misconduct

\section{HOW TO CITE:}

Rossouw TM, Van Zyl C, Pope A. Responsible conduct of research: Global trends, local opportunities. S Afr J Sci. 2014;110(1/2), Art. \#2013-0103, 6 pages. http://dx.doi.org/10.1590/ sajs.2014/20130103

\section{(c) 2014. The Authors.} Published under a Creative Commons Attribution Licence.
Instances of research misconduct reported in the lay and scientific literature as well as international efforts to encourage research integrity and the responsible conduct of research are currently receiving considerable attention. In South Africa, however, the topic has not featured prominently in public debate and clear evidence of a national, coordinated effort to address the problem of research misconduct seems to be lacking. Given increasing globalisation of research efforts, the need exists to promote standardised approaches to interpretation and implementation of the principles and values that underlie responsible conduct of research as well as to create guidelines and structures to promote integrity in research in the country. We explore the notions of research misconduct and research integrity, focusing on initiatives that promote responsible conduct of research, and propose a framework for the South African context.

\section{Introduction}

The topic of responsible conduct of research is currently receiving considerable attention. A reason for this attention is the increasing concern about revelations of fraud and other inappropriate behaviour in the research context. ${ }^{1-3}$ Such revelations often surface in the lay media as high-profile cases and attract negative publicity that not only highlights the harm caused by the individual perpetrator, but also casts doubt on the integrity of the institution or scientific discipline within which the research was conducted. Another reason for the attention is the globalisation of the scientific enterprise and the burgeoning opportunities to work in interdisciplinary, transdisciplinary and applied research environments. In this global context, the need to foster a shared understanding of principles and values that form the foundation of research integrity, and to implement standardised approaches to designing, planning, conducting and administering research, ought to be clear.

The notion of 'responsible conduct of research' is distinguishable from both 'research integrity' and 'research ethics'. 'Research ethics' usually includes the processes in terms of which the proposed research study is scrutinised to assess compliance with the desired values and principles that are part of ethical research. 'Research integrity', on the other hand, has a broader meaning and may be understood to also incorporate implementation of the research processes and the conduct of the researchers. 'Responsible conduct of research' is an umbrella term that includes notions like authorship, plagiarism, research misconduct, whistle-blowing, research ethics guidelines, codes of conduct, conflict of interest, research ethics and other training. The distinction drawn between 'research integrity' and 'responsible conduct of research' is increasingly fading in practice, as is evident in the ensuing discussion in which we employ these terms interchangeably.

All of these concepts, when properly articulated and explained in solid policy and procedure documentation, serve to support and facilitate research conduct so that risks of harm are minimised. Various national and international bodies are currently developing or updating guidelines and policies to promote the responsible conduct of research (National Institutes of Health 2012, InterAcademy Council 2012, European Science Foundation 2011, Council of Canadian Academies 2010, Australian Government 2007, Organization for Economic Cooperation and Development 2007, to name but a few). In 2007, 2010 and 2013, consecutive World Conferences on Research Integrity brought together key role players including researchers, research managers, funders and journal editors in a global effort to foster responsible research. The 2010 Singapore Statement on Research Integrity, ${ }^{4}$ published at the conclusion of the Second World Conference, emphasises the principles and professional responsibilities regarded as essential for integrity in research. While research institutions are held responsible for creating a climate conducive to desirable behaviour, the focus of the Singapore Statement is largely on the researcher: appropriate attitudes and behaviours expected of researchers as professionals are spelled out. ${ }^{4}$

The South African research community has by no means been free from instances of research misconduct., ${ }^{5,6}$ Even if such cases have been dealt with quite decisively by institutions that employ the alleged perpetrators, the misconduct is not, as a rule, made known publicly, or subjected to external scrutiny or censure. There is no oversight body or association of interested entities that has taken on the role of drafting guidelines on responsible conduct of research and no entity mandated to deal directly with allegations or cases of misconduct beyond the institutional level. The National Health Research Ethics Council (NHREC) has an oversight role in the more specialised area of health research ethics, and may deal with complaints or appeals in this field. Even this role is not well known in disciplines beyond health research. Some individual academic and research institutions have endorsed the Singapore Statement, but others are still debating the efficacy of adopting or adapting the Statement and very limited efforts have been made to raise awareness on a national level. ${ }^{7}$

Whereas national and international standards for research ethics have arguably reached levels of maturity in terms of guidelines and application, we point to a need for similar work in related areas that aims to promote the responsible and accountable conduct of research. We explore the notions of research misconduct and research integrity and their importance within the context of responsible conduct of research. We describe the perceived international prevalence of and examine some African researchers' views about research misconduct and why it may occur and also briefly explore initiatives for promoting responsible conduct of research in other countries. Finally, we propose a framework for responsible research conduct for the South African context. 


\section{Background}

Responsible conduct of research, or research integrity, is the cornerstone of excellent research; it also is a prerequisite for a flourishing academic research environment. Various definitions of research integrity exist, including 'the coherent and consistent application of values and principles essential to encouraging and achieving excellence in the search for, and dissemination of, knowledge'8. The Singapore Statement acknowledges different cultural and national standards for scientific research, but maintains that certain principles and professional responsibilities are fundamental to the integrity of research, whatever the context. In other words, the researcher has a personal and professional responsibility to behave ethically and responsibly and to conduct research with integrity. The Singapore Statement articulates four basic principles: honesty in all aspects of research; accountability in the conduct of research; professional courtesy and fairness in working with others; and good stewardship of research on behalf of others. ${ }^{4}$ The principles of honesty and trust are emphasised as the golden threads found throughout the scientific enterprise: society should be able to trust the integrity, accuracy and honesty of scientific results, while researchers should be able to trust the meticulous and honest data capturing, analysis and reporting of results by colleagues. ${ }^{9}$ At an institutional level, integrity is a 'commitment to creating an environment that promotes responsible conduct by embracing standards of excellence, trustworthiness, and lawfulness'8.

Conceptually, research integrity requires adherence to ethical principles and values deemed essential for responsible research conduct, as well as adherence to professional standards set down by oversight bodies such as governmental entities, funding agencies, professional associations and employers. The ideal of research integrity is attained when individual researchers adopt the principles and practices of their profession as a personal credo, rather than merely accept them as impositions. ${ }^{10}$

Similarly, no uniform definition exists for research misconduct, i.e. behaviour that deviates from the accepted standards of research conduct. Early definitions were broad, such as 'non-adherence to rules, regulations, guidelines, and commonly accepted professional codes or norms'11 or 'fabrication, falsification, plagiarism and other serious deviations from accepted practice'12. 'Other serious deviations' were taken to refer to diverse acts such as intentional protocol violations, dropping outliers from a data set or falsification of a biosketch or résumé. Concerns about the vagueness of 'other serious deviations' have led to recent definitions that restrict research misconduct to fabrication, falsification and plagiarism, which are regarded as the key concepts, akin to scientific fraud. For instance, the Office of Science and Technology Policy in the USA defines research misconduct as 'fabrication, falsification or plagiarism in proposing, performing, or reviewing research, or in reporting research results'13.

In our view, such a narrow definition is unsatisfactory as other questionable behaviours could also bring the research profession into disrepute. These behaviours can be grouped together under the term 'questionable research practices' and defined as 'actions that violate traditional values of the research enterprise and that may be detrimental to the research process [but do not] directly damage the integrity of the research process ${ }^{\prime 14}$. We concur with the proposal to separate research practices into three categories: deliberate misconduct - including fabrication, falsification and plagiarism (FFP); questionable research practices (QRP); and responsible conduct of research (RCR). ${ }^{15}$ Here, $\mathrm{RCR}$, or research integrity (RI), represents the expected or ideal standard, FFP denotes very serious transgressions and QRP falls somewhere in between

\section{Exploring the status quo of research misconduct}

Globally, a variety of studies and analyses has attempted to describe and explain the perceived prevalence of, and the causes and costs of research misconduct. Possible preventative measures and remedies are also proposed within these studies. Of particular interest are initiatives that aim to promote RCR in an integrated and coordinated manner, and to establish clear procedures to manage allegations of non-adherence to expected standards. South Africa does not have a national coordinating entity that serves to promote RCR in the country.

A review of existing and emerging initiatives elsewhere was undertaken in order to propose a possible framework for the promotion of RCR in South Africa. The available literature, including policy documents and online resource materials, was surveyed and analysed against the backdrop of recent policy developments in South Africa. Our own experience in supervising research and developing support structures to address or promote RCR added to the contextualisation of the analysis.

\section{Prevalence and impact of scientific misconduct}

The analysis revealed increased interest in the field of research misconduct, yet little agreement about its prevalence. It was further noted that most studies and surveys have methodological concerns and other limitations. Until recently, it was a fairly widely held belief in the research community that FFP occurs rarely - mostly estimated at less than $1 \%$ - and that QRP, even though more prevalent, was usually not considered serious enough to warrant official action. Indeed, confirmed research fraud cases in the USA are variably reported as between 1 in 10000 to 1 in 100000 scientists, depending on the methodology used for calculation. ${ }^{15,16}$ Furthermore, most of the profession held the view that scientific research could regulate itself through mechanisms such as peer review..$^{15}$ However, more recent data reveal that such views might have been overly optimistic.

A study published in 2008 estimated the rate of serious research misconduct or FFP at $3 / 100$ researchers per year. ${ }^{17} \mathrm{~A}$ recent metaanalysis showed that an average of $1.97 \%$ of scientists admitted to have fabricated, falsified or modified data at least once and a further $33.7 \%$ admitted to other QRP. When asked about the behaviour of colleagues, $14.12 \%$ suspected their colleagues of serious research misconduct and $72 \%$ thought colleagues were guilty of QRP. ${ }^{18}$ Although much higher than the previously reported prevalence of $<1 \%$, these data may still be an underestimation of the actual prevalence of research misconduct. Indeed, a recent study in Nigeria - a first for the African continent - reported that $68.9 \%$ of 133 researchers participating in the study admitted to at least one of eight listed forms of scientific misconduct, $42.2 \%$ admitted to FFP and the most common QRP (affecting $36.4 \%$ of the sample) was reported as disagreement about authorship matters. ${ }^{19}$

Retractions from PubMed because of scientific misconduct indicate that up to $0.2 \%$ of published papers contain some form of fraud. ${ }^{20} \mathrm{~A}$ comprehensive study by Grieneisen and Zhang ${ }^{21}$ confirms that, since 2001, retractions have increased dramatically across a range of disciplines, with close to $20 \%$ explicitly citing scientific misconduct as the reason for retraction. Even though this figure represents a very small number of publications $(<1 \%)$, the implications are serious. In particular, suspicion about the trustworthiness of published scientific data is given room to grow. Similarly, the implications also point to the potential risk posed by a new generation of technologically advanced researchers entering the scene. Consequently, the opportunities for research misconduct might increase exponentially, necessitating a more informed and vigilant approach on the part of editors, researchers and research institutions.

Policymakers, researchers and clinicians are also negatively affected by research misconduct, especially fabrication and falsification, as is evidenced by the recent case published in the British Medical Journal. ${ }^{3}$ In this case, a researcher, considered by his peers to be a world leader, was found to have fabricated a very large amount of data and even whole studies. His work had been highly regarded and strongly influenced the formulation of policies and clinical practice. Both policies and practices are now in doubt because reanalysis of the meta-analyses after exclusion of his data radically changed the findings. Consequently, policies influenced by the fabricated work are no longer valid and clinical procedures based on his work also have to be revisited.

\section{Possible causes of research misconduct}

While one can only speculate as to reasons for the difference between the US and Nigerian data, it might be explained partly by lack of awareness, 
institutional support and regulatory oversight in the developing world. In addition, different cultures, generations and disciplines in research may interpret aspects of research misconduct in different ways and accordingly report differently on the prevalence thereof. ${ }^{22}$ Having said that, however, it should be conceded that not much is known about the drivers and facilitators of research misconduct in any context.

In the Nigerian study, $73 \%$ of researchers sampled cited the need for publications as a push factor, ${ }^{19}$ a view shared by research coordinators in the USA. ${ }^{23}$ The worldwide drive to improve university rankings, resulting in part in the pressure to publish, is regarded as one cause of an increased incidence of plagiarism and QRP, such as so-called 'salami-slicing'.24,25 More than $50 \%$ of the Nigerian researchers sampled thought that competition for external funding, the need for peer recognition, as well as insufficient explicit censure of misconduct strongly influence the prevalence of questionable behaviour. ${ }^{19}$ This finding is important because it implies that the research community colludes in the facilitation of wrongdoing by remaining silent instead of speaking out. Not only does this finding highlight the need for a solid ethical foundation for researchers, but it also underscores the imperative of creating national standards for promoting $\mathrm{RI}$ and enabling institutional oversight.

In addition, pressure to gain tenure, unclear definitions of misconduct, financial conflicts of interest as well as the level of involvement of the principal investigator in the enrolment of human participants were considered by the majority of the Nigerian sample to have 'some influence' on questionable behaviour patterns. The level of interest shown by the principal investigator in study enrolments and outcomes, the number of open or current research studies for which the principal investigator is responsible, and the belief that the risk of harm for participants is low in a study also contribute to lax attitudes towards questionable behaviour patterns. ${ }^{19}$

It is vital that further context-specific research into possible facilitators of research misconduct be conducted in order to inform future training and guide policy frameworks.

\section{Initiatives to promote responsible conduct of research}

Recently, national and international bodies have developed policy documents that focus on RCR as an integrated construct that includes all phases and aspects of the research endeavour. In these documents, specific responsibilities are allocated to individual researchers, to research institutions and to oversight bodies. Examples of such initiatives can be found across the globe. Approaches to oversight range from countries with national guidelines and government-sponsored offices for statutory reporting and oversight, to national or regional interest groups promoting coordination between institutions, to countries where no national guidelines or oversight bodies exist.

An example of a country with a national guideline is Australia. The Australian Code for the Responsible Conduct of Research was developed through a collaborative effort of the National Health and Medical Research Council, the Australian Research Council and Universities Australia. The purpose of the Australian Code is to guide institutions and researchers in responsible research practices. The Australian Code includes specific guidance on how to manage breaches of the Code and allegations of research misconduct, maintain research data and material, publish and disseminate research findings, attribute authorship, conduct effective peer review, and manage conflicts of interest. ${ }^{26}$ Another example of a country with a well-developed national guideline is Canada, where the Tri-Council policy statement fulfils a similar function to the Australian Code. ${ }^{27}$

More recently, triggered by the globalisation of research, international declarations, such as the Singapore Statement on Research Integrity ${ }^{4}$ and the 2012 policy work of the global network of science academies and the IAP22, have been formulated. These documents reflect consensus amongst the individual researchers present, e.g. participants at the Second World Conference on Research Integrity contributed to the creation and adoption of the Singapore Statement. The relatively short and succinct Statement calls for the globalisation of a basic understanding of RCR and is the 'first international effort to encourage the development of unified policies, guidelines and codes of conduct'4. The aim of the Statement is to initiate a global discussion on RI and the development of a set of international norms and standards that can serve as the basis for national and regional ethics guidelines, while acknowledging and accommodating national differences. The Statement can be a valuable tool to countries such as South Africa, for which no national guidelines or oversight bodies exist.

\section{The South African context}

Despite instances of local research fraud receiving international attention, South Africa has not introduced a system of formal scrutiny or censure. A National Health Research Ethics Council (NHREC) was established in terms of the National Health Act $61 / 2003 .{ }^{28}$ Its role is to provide guidance for researchers in health research, principally regarding research ethics and not RI as such. For instance, the NHREC is responsible for ensuring that up-to-date research ethics guidelines are available and accessible, and for assisting with complaints, queries and capacity building for research ethics committees. The NHREC has a Complaints and Advisory Disciplinary Committee, mandated to 'refer to the relevant statutory health professional council matters involving the violation or potential violation of an ethical or professional rule by a health care provider' and to 'institute such disciplinary action as may be prescribed against any person found to be in violation of any norms and standards, or guidelines, set for the conducting of research' 28,29 . However, this committee's jurisdiction is limited to protection of human participants and animals used in research, hence cases involving allegations such as plagiarism or data fabrication fall outside its mandate.

In the absence of national guidelines or codes of conduct specific to $\mathrm{RCR}$, much reliance is placed on professional codes of conduct guiding the behaviour of individual researchers, or on institutional guidelines to promote the responsible and ethical conduct of research. The NHREC also favours the approach that institutions should first attempt to resolve matters internally before referring them to the NHREC. This view is consistent with the administrative law rule that one exhausts domestic remedies before seeking outside adjudication. This approach supports the autonomy of institutions and their power to govern themselves, which is statutorily mandated. On the other hand, this approach may inadvertently disadvantage institutions that lack the know-how, resources and infrastructural support to deal with allegations and cases of misconduct. It is further possible that at individual institutions there might be reluctance to engage effectively with researchers, especially high-profile researchers, alleged to have committed research misconduct, because of an inherent conflict of interest. ${ }^{30}$ Such attitudes could lead to examples of unequal treatment of similar incidents between and even within institutions. A centralised office might be better placed to ensure a fair and equitable approach by establishing national guidelines on the appropriate procedures to be followed in cases of alleged and confirmed misconduct. Even though it is preferred that institutions deal with such matters internally, a centralised office could also function as an adjudicatory or referring body for instances when individual institutions are unable to resolve cases, procedures are disputed or conflicts of interest exist.

However, the NHREC is mandated to deal only with matters concerning health research. In increasingly complex research arenas, it seems desirable to cross institutional and disciplinary boundaries by promoting harmonised approaches to interpretation and implementation of principles and values underlying RCR. A problem for South Africa is that the various documents outlining science policy for the country (e.g. Department of Arts, Culture, Science and Technology White Paper 1996, National Research and Development Strategy 2002, Ten-Year Plan for Innovation 2008, Ministerial Review Report 2012) are silent on key aspects of research ethics and integrity, and miss the opportunity to create guidelines and structures to promote the quality and responsible conduct of research in the country. The 2012 Ministerial Review Report suggested that a national oversight body for science policy should be established. Such a body could establish guidelines for a national system 
or structure(s) to promote RCR, and to respond to possible research misconduct. This body could provide the needed transdisciplinary leadership for guiding the prevention, investigation and correction of research misconduct, while ensuring that research institutions remain primarily responsible for management of individual cases.

Whether a centralised approach is desirable has not been debated in public fora in South Africa. Informally, it seems that opinions are divided: some think that a central bureaucracy is desirable given the attraction of consistency, standardisation and institutional support; others favour the autonomy of research institutions in dealing with allegations of misconduct expeditiously, discreetly and effectively. Bureaucracies are not easily able to act in this way. Furthermore, a centralised approach has considerable specific human and financial resource requirements and is likely to not be the most time- and cost-effective approach in a country with limited resources.

On an individual level, South African researchers have contributed to the international debate. Representatives from the National Research Foundation (NRF) and the Academy of Science of South Africa attended the 2010 World Conference on Research Integrity and the NRF subsequently promoted broader awareness of the Singapore Statement on Research Integrity. ${ }^{7}$ It seems that some South African institutions of higher learning and other research entities are adopting this document as a reference point, which might signal the dawn of a shared understanding of $\mathrm{Rl}$ in the country.

\section{Proposed framework for South Africa}

A culture of research excellence and $\mathrm{RI}$ requires contributions from actors and interest groups that operate at different levels and in a range of roles and responsibilities. Initiatives to promote RCR should therefore be multipronged and aimed at multiple and diverse role players. Using the categories included in the 2012 InterAcademy Council policy document ${ }^{22}$ as a point of departure, we propose the inclusion of the following actors in the South African framework:

- Individual researchers: Researchers are the foundation of sound scientific practice and need to be imbued with strongly developed moral and ethical reasoning skills. They are required to embrace, uphold and promote professional standards of research excellence in their own research work and when reviewing the work of others. In addition, the notion of RCR requires them to actively promote appropriate conduct in their teaching and mentoring relationships.

The South African research community would benefit from improved communication systems designed to provide guidance and support in order to promote RCR. In particular, researchers should reflect on their own knowledge and understanding of RCR and contribute to discussions, at least at their own institutions. In this way, the valuable intellectual capital of our researchers may be shared and invested in sustaining the research enterprise in South Africa.

- Research and academic institutions: Within institutional settings, an environment conducive to RCR may be fostered by having appropriate and clear policies and procedures. These policies and procedures should stipulate how cases of alleged or suspected misconduct should be managed. This recommendation does not call for more regulation or for an infringement of institutional autonomy or academic freedom. Rather, we recommend frank and rigorous discussions, and careful and thoughtful reflections, so that where systems may be weak, support can be given and best practices may be shared.

- Editorial boards and publishers of scientific journals: Researchers who submit research outputs for publication in scholarly journals should provide proof of ethics approval of the research undertaken, as well as a clear indication of authorship allocations. This requirement is already specified by many journals. Furthermore, plagiarism-checking software has improved the ability to trace incidents of plagiarism and should be used routinely. Recently, after the case of research misconduct reported in the British
Medical Journal, some commentators are also now calling for all authors to verify that they have seen the original data. ${ }^{3}$

- National and international professional organisations: In the past decade, these organisations have done much to give prominence to responsible research conduct and the promotion thereof. Examples include recent reports of interacademy councils in Canada $(2010)^{8}$, Europe $(2010)^{31}$ and internationally $(2012)^{22}$. World conferences dedicated to RI are supported by funding bodies, science academies and professional associations and can act as a platform to raise awareness and share resources. South African institutions should be encouraged to actively participate in and contribute to these international debates.

- National governments and government departments: Government is in a position to provide support for, or actively promote, the RCR. Although South Africa has national guidelines and oversight in relation to ethics in health-related research (i.e. The National Health Act ${ }^{28}$ and the South African Good Clinical Practice Guidelines ${ }^{32}$ ), it lacks similar guidelines and oversight to promote and provide guidance in relation to other aspects of RCR. Government departments can play a role by making funding available to support the development and sharing of guidelines that can become a national repository of best practice and resource for independent guidance when required. In particular, we recommend that the Singapore Statement be incorporated into the national research ethics collection of guidelines, either by reference or by a statement endorsed by various research bodies.

- Funding bodies: The exact role of funders in promoting RI is controversial. While there are justified concerns about the perils of funders setting the research agenda and issues around effective and appropriate oversight, funders may play a role by insisting, as a prerequisite to funding eligibility, that minimum standards for policies and procedures to promote RCR are in place. Funding bodies may also introduce additional mechanisms aimed at promoting responsible research practices, such as independent post-submission reviews of reports which may include standard checks for possible examples of plagiarism or standard contractual requirements dealing with authorship agreements, or open access to data or research findings. Furthermore, funding bodies are in a position to support research about aspects of $\mathrm{Rl}$, as well as the development of training materials and programmes. It should be noted, however, that funding bodies do not have direct jurisdiction over the quality and integrity of research not funded by them, hence a case being made for generic norms and standards to be adopted at national or international level.

The NRF could potentially play such an enabling role in South Africa. The NRF has already indicated that it will be investigating ways of implementing the Singapore Statement, for instance, by making the implementation of its principles a prerequisite for grant agreements with grantholders. The NRF has further committed itself to 'translate the statement into South Africa's eleven official languages and to disseminate it widely amongst research institutions and government departments'?.

- $\quad$ Research networks and ethics training programmes: Research networks and professional associations provide platforms for the exchange of information and shared learning. There are well-established South African examples of relevant professional and training networks, such as the South African Research Ethics Training Initiative (SARETI), the Southern African Research and Innovation Management Association (SARIMA) and Advancing Research Ethics Training in Southern Africa (ARESA) which replaces the International Research Ethics Network for Southern Africa (IRENSA).

These networks currently focus specifically on research ethics, as do most of the online training programmes that have been developed by international institutions and consortiums, such as Training and Resources in Research Ethics Evaluation (TRREE) 
and the African Malaria Network Trust (AMANET). Some of these programmes deal with RCR, but the focus is mostly tangential. If this aspect could be further developed and strengthened, these programmes could become a valuable resource for all researchers, and institutions could consider incorporating them into continued professional development curricula.

\section{Conclusion}

Revelations of research misconduct are embarrassing for journals and academic institutions, deleterious to the research enterprise in general and disastrous for the researcher who is found to have cheated. The advent of easy access to information through electronic media, coupled with a new generation of technologically advanced researchers faced with ever increasing pressure to publish and secure funding, mean that opportunities for research misconduct might increase in future. In addition, the globalisation of the scientific enterprise and increasing opportunities for interdisciplinary and international research, highlight the need for a shared understanding of the principles and values that inform the notion of RI.

South Africa, despite being home to some high-profile instances of research misconduct, has not yet escalated the problem of research misconduct to the level of public debate and has not yet embarked on a national and unified effort to put systems in place for its regulation. Although individual researchers and research institutions have been party to the international debate and have endorsed the Singapore Statement, many institutions lack the resources and infrastructure to follow suit. We therefore support the development of coordinated approaches to designing, planning, conducting and administering research, in conjunction with appropriate and clear policies and procedures stipulating how cases of alleged or suspected misconduct should be managed. We do not call for more regulation or for an infringement of institutional autonomy or academic freedom, but rather for the establishment of policies and guidelines that should form part of a national repository of best practice and resource for independent guidance when required.

We propose that multiple role players be involved in establishing a South African framework for RCR, including research and academic institutions, editorial boards, professional organisations, government departments, funding bodies and research networks. Such a framework could then be maintained and implemented by a centralised body, such as an Office of Scientific Research Integrity. The vision of an honest and trustworthy research enterprise can, however, only be realised when individual researchers have been imbued with the strongly developed moral character needed to embrace, uphold and promote professional standards of research excellence.

\section{Authors' contributions}

T.R. conceived the idea and wrote the first draft. C.v.Z. and A.P. gave significant intellectual input; C.v.Z. specifically contributed significantly to the section on international initiatives and the proposed framework for South Africa. C.v.Z. and A.P. assisted in revising and refining the draft into its current format. All three authors read and approved the final version.

\section{References}

1. Marc Hauser engaged in research misconduct. Harvard Magazine [serial on the Internet]. 2012 Sep 05 [cited 2013 Mar 05]. Available from: http:// harvardmagazine.com/2012/09/hauser-research-misconduct-reported.

2. Pelley S. Deception at Duke: Fraud in cancer care? [homepage on the Internet] c2012 [cited 2013 Mar 05]. Available from: http://www.cbsnews.com/830118560_162-57376073/deception-at-duke-fraud-in-cancer-care/

3. Wise J. Research misconduct. Boldt: The great pretender. BMJ. 2013;346:f1738.

4. 2nd World Conference on Research Integrity. Singapore statement on research integrity [homepage on the Internet]. c2010 [cited 2012 0ct 12]. Available from: www.singaporestatement.org.

5. Gottlieb S. Breast cancer researcher accused of serious scientific misconduct. BMJ. 2000;320(7232):398.
6. Sidley P. Another AIDS "cure" scandal hits South Africa. BMJ. 1998;316(7146):1696. http://dx.doi.org/10.1136/bmj.316.7146.1696f

7. National Research Foundation Emerging Researchers Network. Singapore Statement on research integrity receives thumbs up [homepage on the Internet]. c2011 [cited 2013 March 21]. Available from: http://ern.nrf.ac.za/ control/ViewFeatureArticle?contentld $=11188 \&$ featureContentld $=11188 \&$ ar ticleType $=$ mainFeature

8. Council of Canadian Academies. The expert panel on research integrity. Honesty, accountability and trust: Fostering research integrity in Canada. Ottawa: Council of Canadian Academies; 2010.

9. National Academy of Sciences, National Academy of Engineering, Institute of Medicine, Committee on Science, Engineering, and Public Policy. On being a scientist: Responsible conduct in research. 2nd ed. Washington DC: National Academy Press; 1995.

10. Korenman SG. Teaching the responsible conduct of research in humans [homepage on the Internet]. c2006 [cited 2012 0ct 10]. Available from: www. ori.hhs.gov/education/products/ucla/chapter1/page02.htm.

11. Broome ME, Pryor E, Habermann B, Pulley L, Kincaid H. The scientific misconduct questionnaire-revised (SMQ-R): Validation and psychometric testing. Account Res. 2005;12(4):263-280. http://dx.doi. org/10.1080/08989620500440253

12. Buzzelli $D E$. The definition of misconduct in science: A view from NSF. Science. 1993;259(5095):584-585. http://dx.doi.org/10.1126/science.8430300

13. United States Office of Science and Technology Policy. Federal Policy on Research Misconduct. Federal Register. 2000;65(235):76260-76264.

14. National Academy of Science, Committee on Science Engineering and Public Policy, Panel on Scientific Responsibility and the Conduct of Research. Responsible science: Ensuring the integrity of the research process. Washington DC: National Academy Press; 1992.

15. Steneck NH. Fostering integrity in research: Definitions, current knowledge, and future directions. Science and Engineering Ethics. 2006;12:53-74.

16. Marshall E. Scientific misconduct - how prevalent is fraud? That's a milliondollar question. Science. 2000;290:1662-1663. http://dx.doi.org/10.1126/ science.290.5497.1662

17. Titus SL, Wells JA, Rhoades LJ. Repairing research integrity. Nature. 2008;453(7198):980-982. http://dx.doi.org/10.1038/453980a

18. Fanelli D. How many scientists fabricate and falsify research? A systematic review and meta-analysis of survey data. PLoS One. 2009;4(5):e5738. http:// dx.doi.org/10.1371/journal.pone.0005738

19. Okonta P, Rossouw T. Prevalence of scientific misconduct among a group of researchers in Nigeria. Dev World Bioeth. 2013;13(3):149-157. http://dx.doi. org/10.1111/j.1471-8847.2012.00339.x

20. Claxton LD. Scientific authorship. Part 1. A window into scientific fraud? Mutat Res. 2005;589(1):17-30. http://dx.doi.org/10.1016/j.mrrev.2004.07.003

21. Grieneisen ML, Zhang M. A comprehensive survey of retracted articles from the scholarly literature. PLOS ONE. 2012;7(10):e44118. http://dx.doi. org/10.1371/journal.pone. 0044118

22. InterAcademy Council / IAP. Responsible conduct in the global research enterprise: A policy report. Amsterdam: Bejo Druk \& Print, Alkmaar; 2012. Available from: http://www.interacademies.net/File.aspx?id=19789.

23. Fletcher SW, Fletcher RH. Publish wisely or perish: Quality rather than quantity in medical writing. Ann Acad Med Singapore. 1994;23:799-800.

24. Jefferson T. Redundant publication in biomedical sciences: Scientific misconduct or necessity? Sci Eng Ethics. 1998:4(2):135-140. http://dx.doi. org/10.1007/s11948-998-0043-9

25. Roig M. Avoiding plagiarism, self-plagiarism, and other questionable writing practices: A guide to ethical writing [document on the Internet]. No date [cited 2013 Mar 12]. Available from: http://ori.dhhs.gov/education/products/ plagiarism/plagiarism.pdf.

26. Australian Government. Australian code for the responsible conduct of research [document on the Internet]. c2007 [cited 2012 0ct 15]. Available from: http:// www.nhmrc.gov.au/_files_nhmrc/publications/attachments/r39.pdf. 
27. Canadian Institutes of Health Research, Natural Sciences and Engineering Research, Council of Canada, and Social Sciences and Humanities Research Council of Canada. Tri-Council policy statement: Ethical conduct for research involving humans [document on the Internet]. c2010 [cited 2013 Mar 22]. Available from: http://www.ethics.gc.ca/pdf/eng/tcps2/TCPS_2_FINAL_Web.pdf.

28. Republic of South Africa. National Health Act No. 61 of 2003. Government Gazette. 2004;469(26595).

29. National Health Research Ethics Council. Guidelines for the management of complaints. Complaints and Advisory Disciplinary Committee [document on the Internet]. c2012 [cited 2013 Aug 26]. Available from http://www.nhrec. org.za/wpcontent/uploads/2013/guideline_mngcomplnt.pdf.
30. Ana J, Koehlmoos T, Smith R, Yan LL. Research misconduct in low- and middle-income countries. PLoS Med. 2013;10(3):e1001315. http://dx.doi. org/10.1371/journal.pmed.1001315

31. European Science Foundation. Fostering research integrity in Europe: A report by the ESF Member Organisation Forum on research integrity [homepage on the Internet]. c2010 [cited 2013 Mar 05]. Available from http://www.esf.org/ activities/mo-fora/publications.html.

32. Department of Health. Guidelines for good practice in the conduct of clinical trials with human participants in South Africa. Pretoria: Department of Health; 2006. 